\begin{tabular}{llllllll}
$\mathbf{R}$ & $\mathbf{E}$ & $\mathbf{C}$ & $\mathbf{E}$ & $\mathbf{N}$ & $\mathbf{Z}$ & $\mathbf{J}$ & $\mathbf{E}$ \\
\hline
\end{tabular}

\title{
BOOK ON THE INSCRIPTION FOR BURYING A CRANE AND THE ART OF CHINESE CALLIGRAPHY
}

Lei Xue. Eulogy for Burying a Crane and the Art of Chinese Calligraphy.

University of Washington Press, 2019, xii +220 pp., hardcover. ISBN:

9780295746364.

DOI: http://doi.org/10.18290/rh21699-10

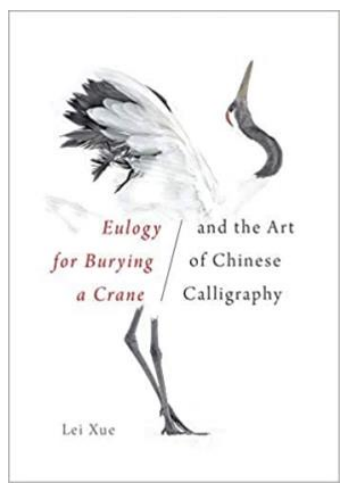

There is a very special connection between handwritten calligraphy and epigraphy in China. These two strongly impacted each other for hundreds of years. Texts written with a brush were sometimes eternized in stone, and inscriptions carved in stone often became models for brush calligraphy. Usually they circulated among the lovers of calligraphy in the form of ink rubbings. However, many stone inscriptions are anonymous. We don't know the names of the authors and carvers of these texts. Or, if there are such names, we are often unable to tell anything about their bearers (Brown 30-31). One of such mysterious texts is $Y i$ he ming 痤鶴銘, Inscription for Burying a Crane, whose history is a fascinating example of a dynamic interrelation of a range of cultural phenomena. The story of $Y i$ he ming has inspired dozens of scholars, and recently professor Xue Lei has conducted a case study of the inscription, and published a book Eulogy for Burying a Crane and the Art of Chinese Calligraphy.

Professor Xue teaches at the Art Department of Oregon State University. He studied literature at Beijing Normal University. In 2009, he earned his PhD in Chinese art at Columbia University under Robert E. Harrist, Jr.

MARek PiszczeK, MA - University of Warsaw, sinologist and librarian, teaches Chinese art at the Faculty of Oriental Studies; address for correspondence: Krakowskie Przedmieście 1, p. 9, 00-047 Warszawa, e-mail: marek.piszczek@uw.edu.pl. ORCID: https://orcid.org/0000-0003-3587-9038. 
In the past, several people made research on $Y i$ he ming, with the first monograph by Gu Yuanqing 顧元慶, published in the Ming Dynasty, followed by the important studies by the early Qing scholars Zhang Chao 張弨 and Wang Shihong 汪士鋐. In modern times, probably the most comprehensive publication was Zhongguo Zhenjiang Yi he ming guo ji xue shu yan tao hui lun wen hui bian 中國鎮江痤鶴銘國際學 術研討會論文彙編, edited by Ding Chao 丁超. Xue Lei's unpublished doctoral dissertation was also devoted to the subject of $Y i$ he ming. The present book by professor Xue is the first single-author scholarly publication of a magnitude similar to Ding Chao's collected papers. But it has at least two additional advantages. It applies the Western research attitude, and having been written in English, it is available to an international reader.

In the introduction, Xue describes a popular reception of $Y i$ he ming in the past centuries, which was based on a legend about famous calligrapher Wang Xizhi 王羲之 buying cranes at a temple on the Island of Jiaoshan 焦山, in the vicinity of Zhenjiang, Jiangsu. From the very beginning, the book brings the reader into an enigmatic aura of this unique inscription, and leads him step by step in search for its authorship, history and meaning.

The introduction includes concise explanation of some important and basic issues pertaining to the history of Chinese calligraphy: Xue discusses the phases of its development, different types of Chinese script, kinds of strokes in a Chinese character, the practice of making fatie 法帖 (model books) and ink rubbings.

In chapter one Xue precisely describes the present physical condition of $Y i$ he ming. He reconstructs its text, and translates it to English. Then he discusses the role and symbolism of a crane in Chinese culture. The word ming 銘 in the title of the inscription as well as the composition of its text suggest that $Y i$ he ming belongs to a literary genre of epitaph. Therefore professor Xue, being well versed not only in the history of art but also in literature, explains the phenomenon of epitaph in the early and medieval China, and points out the aspects of its textual uniqueness. The material format of $Y i$ he ming as an epitaph is unusual, too. It was not engraved in a stone slab but chiseled with big characters on a cliff. This category of inscriptions is called moya 摩崖 in Chinese, and Xue devotes some space to discuss its nature and role in Chinese landscape. After that he describes the environment of $Y i$ he ming, which seems to resemble a mausoleum or Taoist land of immortals. At the end of the chapter Xue proposes a solution to the issues of authorship and reasons of creating the inscription.

Soon after having been carved, Yi he ming seemed to stay forgotten for the next several centuries. It reappears though in the texts of the Song Dynasty. And to this particular period in the history of the inscription chapter two is devoted. The author ponders on possible reasons why we don't have any written information on Yi he ming from the pre-Song times. He also attempts to explain the origin of the legend in which Yi he ming was connected to Wang Xizhi. Then he describes the first scholarly approaches to the inscription. What is worth mentioning is the fact that the $11^{\text {th }}$ century 
pioneers of epigraphy in China treated $Y i$ he ming like an interesting cultural relic, but few of them deemed it important as a calligraphic model. The best known Song calligrapher who drew inspiration from Yi he ming was Huang Tingjian 黃庭堅. Xue discusses how his calligraphy was influenced by the inscription. The book also emphasizes that according to the popular belief of those times, $Y i$ he ming was a work of Wang Xizhi. That was a major reason why gradually more and more people pilgrimaged to Jiaoshan Island, sometimes leaving their own inscriptions to commemorate their visit at the famous site - a practice similar to writing colophons on handscrolls of calligraphy (Xue enumerates the dated cliff inscriptions on Jiaoshan Island in appendix one). At that time the first stone replicas of $Y i$ he ming were made.

Chapter three discusses the perception of $Y i$ he ming during the Ming Dynasty. Under the Mongol rule and at the beginning of Ming the popularity of the inscription diminished. Such was a general tendency in so called "bronze and stone studies" at that time (McNair 112). In the middle Ming period a new wave of interest in epigraphic studies arose. Xue explains the socio-cultural changes that led to it. Among the important factors, he mentions publishing private fatie, and inclusion of $Y i$ he ming in one of such publications.

In conclusion Xue Lei discusses two interesting cultural paradoxes concerning $Y i$ he ming. First, he reveals that what was done to protect the esteemed inscription actually accelerated its damage. At the turn of the $17^{\text {th }}$ and $18^{\text {th }}$ centuries some scholars appeared who in quest for real facts examined $Y i$ he ming anew, reconstructed its text, and gathered the extant broken fragments of the cliff in a newly built pavilion. It was done on the one hand for the convenience of guests visiting the island, but on the other hand to prevent further erosion of the inscription. Xue proves, however, that people coming to Jiaoshan in the $18^{\text {th }}$ century made so many ink rubbings of $Y i$ he ming that the condition of the relic deteriorated much faster than when it was partly resting under water. The second paradox is that only after getting more blurred than ever was the inscription elevated to the role of excellent calligraphy model, and it happened when the school of stelae (bei pai 碑派) emerged. The last part of conclusion of the book presents the latest history of $Y i$ he ming. Xue indicates there how the inscription is used in popular culture, local tourism promotion, and even strengthening of nationalism.

Xue has analyzed several source texts and visual materials from consecutive epochs. Besides, the bibliography comprises art-historical, literature, cultural, and archaeological publications in English, Chinese, Japanese, French and German. Xue did a fieldwork at the site of $Y i$ he ming, and used some materials form Jiaoshan Stone Inscription Museum.

The list of references in the book is very extensive. It comprises numerous sources and treatises pertaining to the subject in discussion. For some reason, however, there are no publications by Hua Rende 華人德 (one of the greatest experts in Chinese epitaphs). 
It is not clear for whom the book was written. Some of the information (like the types of strokes in a Chinese character) seems to be obvious to any reader who has a basic command of the Chinese language, and knows anything about writing with a brush. But on the other hand, some issues (like the question of bifa 筆法) might be challenging to someone who has just started learning about the structure of Chinese characters. For the most part, the book discusses issues demanding specialized knowledge, therefore the above mentioned rudimentary explanations seem a little unnecessary.

However, generally speaking, the book presents a splendid, meticulous research with multidisciplinary approach. Xue's aim is not to present a broad panorama of Chinese calligraphy, but to paint a true picture of the meaning of Yi he ming in its historical and cultural context. And this undertaking has proved very successful. It is indeed a multidimensional vision of the famous inscription, comprising the changing trends among Chinese scholars and calligraphers throughout fifteen centuries.

One of reflections after reading the book is that $Y i$ he ming would have probably shared the fate of many moya inscriptions, which remained for ages in oblivion as works of unknown calligraphers, had it not been attributed to the "calligraphy sage" Wang Xizhi. Though this attribution seems completely baseless, somewhere in the early Song the inscription ceased to be anonymous (at least in popular perception), and having been connected to the famous name, Yi he ming was esteemed by many people for the next ages.

Another thought-provoking information in the book pertains to the partial illegibility of $Y i$ he ming. The more blurred the inscription became with passing ages, the greater calligraphic value seemed to be discovered in it. Sometimes it is hard to tell which is greater: the intrinsic artistic value of a work, or the relation of a work with the name of a revered artist (by authorship or attribution). In the case of Yi he ming, we can say that the role of the latter was much more important. One can also see how chasing vanity sustains the life of a myth.

At the end of the book Xue poses a few interesting questions about the role of antiquity in Chinese culture, and the possible alternative history of $Y i$ he ming. I'd like to finish this review with a question, too.

While reading the story of the inscription form Jiaoshan, one may think of some other famous works of Chinese culture, like paintings by Wu Daozi 吳道子, or Wangchuan Garden 輞川 of Wang Wei 王維 from the Tang Dynasty. Those objects were very famous in their era, and they vanished shortly thereafter. In the following centuries nobody really knew what they were like. But Wu Daozi has been regarded as the greatest painter of all times, and Wangchuan Garden has ever remained an unrivalled ideal in gardening. Would therefore $Y i$ he ming has become even more important and occupy a higher place in popular social awareness, if it had got completely lost, for example, during the Mongol conquest? I don't know the answer, but I believe it would be possible. 


\section{BIBLIOGRAPHY}

Brown, Shana J. Pastimes: From Art and Antiquarianism to Modern Chinese Historiography. University of Hawai'i Press, 2011.

McNair, Amy. "Engraved Calligraphy in China: Recension and Reception." The Art Bulletin, vol. 77, no. 1, 1995, pp. 106-14. Doi: doi.org/10.2307/3046083.

Reproduction of the cover from the website: uwapress.uw.edu/book/9780295746364/ieulogy-forburying-a-cranei-and-the-art-of-chinese-calligraphy/. Accessed 5 Feb. 2021. 